Received $1^{\text {th }}$ August 2018,

Accepted $13^{\text {th }}$ August 2018

Link to DOI:

10.25220/WNJ.V02.i1.0007

\title{
Effective Communication Skill: Doctor - Patient Consultation
}

\author{
Saptawati Bardosono, MSc, ${ }^{1}$ Pittara Pansawira, ${ }^{2}$ Mia Puspita Ratih, ${ }^{2}$ \\ 1. Department of Nutrition, Faculty of Medicine Universitas Indonesia \\ 2. Indonesian Nutrition Association \\ 3. Indonesian Nutrition Association
}

Journal website:

Everyone, including physicians/doctors knows how to communicate. Communication skill involves how we apply a systematic cycle of sending message, receiving and interpreting it before we give a feedback. However, people only perceived communication as practicing sending the message. And, when receiving a message the feedback-step is the most often neglected. Actually, the feedbackstep is the most critical part in which it closes the communication cycle and confirms the understanding of the message.

Furthermore, there is a deeper development of communication in which we need to stress into three approaches, i.e. being present, active listening and active empathy. By being present then we can clear the clutter of mental distraction and focus on the immediate communication task at hand. Active listening is needed to apply specific listening-forunderstanding techniques that confirm awareness, while active empathy is important to process information for a true awareness of other's needs. All this approaches take times, of course, however we can anticipate it by practicing effective communication.

The failure to communicate can occur

Coresponding Author:

Saptawati Bardosono, MSc

Departmen of Nutrition Faculty of Medicine Universitas

Indonesia, Jakarta.

Email addres : tati.bardo@yahoo.com everywhere in medical practices. We know that in medical world doctors, nurses, medical staff, administrators and office employee communicate with patients, especially doctors. In dealing with patient interaction, research confirms that "no matter how knowledgeable a clinician/doctor might be, if he or she is not able to open effective communication with the patient, then he or she may be of no help."

Doctors are not born with excellent communication skills, as they have different innate talents. Instead they can understand the theory of good doctor-patient communication, learn and practice these skills, and be capable of modifying their communication style if there is sufficient motivation and incentive for self-awareness, selfmonitoring, and training. ${ }^{1,2}$ Communication skills training has been found to improve doctor-patient communication. $^{3,4}$ However, the improved behaviors may lapse over time..$^{5}$ Therefore, it is important to practice new skills, with regular feedback on the acquired behavior. ${ }^{5}$ Some have said that medical education should go beyond skills training to encourage physicians' responsiveness to the patients' unique experience. ${ }^{6}$

There are several reasons for doctors to sharpen their effective communication skills which include:

1. Ability to successfully interact with a "difficult" patient 
2. Clearly presenting diagnosis and/or References treatment options

3. Enhancing patient's compliance with medications or treatments

4. Gaining a clear understanding of patient needs or medical issues

5. Influencing a patient to adopt healthy living or lifestyle changes.

We realize and understand that the many years of professional medical education are considered lacking in the development of good effective communications skills. Fortunately, there are many options for training to polish the effective communication skills in a real-world application for doctors and other medical staffs.

Indonesian Nutrition Association, with their annual event of Nutri Symposium, held a pre symposium workshop of effective communication skill focusing on weight management, targeting participant with medical background (general practitioners and specialist), with a one day workshop to focus on the implementation of consultation practice followed by simulation on how to present the right understanding of patient needs and influencing them in a lifestyle changes and by result, a satisfactory compliance.

This event will regularly be held each year as a solution for doctors who has a difficulties in communication skills to enhance their consultation daily practice.

\section{Open Access}

This article is distributed under the terms of the Creative Commons Attribution 4.0 International Licence

(http://creativecommons.org/licenses/by/4.0/), which permits unrestricted use, distribution, and reproduction in any medium, provided you give appropriate credit to the original author(s) and the source, provide a link to the Creative Commons license, and indicate if changes were made.

. Lee S. J., Back A. L., Block S. D., Stewart S. K. Enhancing physician-patient communication. Hematology Am Soc Hematol Educ Program. 2002;1:464-483

2. Roter D. L., Hall J. A., Aoki Y. Physician gender effects in medical communication: a meta-analytic review. JAMA. 2002;288((6)):756-764

3. Harms C., Young J. R., Amsler F., Zettler C., Scheidegger D., Kindler C. H. Improving anaesthetists' communication skills. Anaesthesia. 2004;59((2)):166-172

4. Bensing J. M., Sluijs E. M. Evaluation of an interview training course for general practitioners. Soc Sci Med. 1985;20((7)):737-744

5. Brown J. B., Boles M., Mullooly J. P., Levinson W. Effect of clinician communication skills training on patient satisfaction: a randomized, controlled trial. Ann Intern Med. 1999;131((11)):822-829

6. Stewart M., Brown J. B., Donner A., et al. The impact of patient-centered care on outcomes. J Fam Pract. 2000;49((9)):796804. 